Victoria Margree,

Neglected or Misunderstood:

The Radical Feminism of Shulamith Firestone,

Winchester: Zero Books, 2018, 168 pp

\title{
Imagining the Feminist Revolution
}

CAROL HARRINGTON

Shulamith Firestone's The Dialectic of Sex: The Case for Feminist Revolution, first published in 1970, is often remembered for promoting a dystopian vision of babies developing in artificial wombs. ${ }^{1}$ Feminists critiqued Firestone for taking a reductionist approach to women's oppression because she saw it arising from biological reproduction. Victoria Margree's re-visiting of Firestone's work makes a persuasive case that she has often been misunderstood and has continuing relevance for feminism. Neglected or Misunderstood grew from Margree's 10 years of teaching Firestone, which may explain its engaging pedagogical voice. In the 12 bite-sized chapters of this short book, Margree systematically takes readers through different elements of Firestone's argument, making an intriguing case for her historical-materialist account of women's oppression as based in human reproduction.

Margree introduces The Dialectic of Sex as a feminist manifesto, which Firestone, aged 25, wrote over a few months in 1969. As she notes, "like all manifestos it is characterized by "compression" and "hyperbole", a helpful observation for the reader confronting Firestone's lurid characterisation

1 Shulamith Firestone, The Dialectic of Sex: The Case for Feminist Revolution (New York: Bantam Books, 1971). 
of pregnancy and childbirth and her visions of technologically facilitated reproduction as a desirable norm. ${ }^{2}$ Chapters one and two argue for a return to Firestone and provide some historical context-for example, reminding us that when Firestone wrote, only married women could easily access contraception in the US, while abortion was illegal in most states. Chapters three to eight systematically consider the core arguments of The Dialectic of Sex, offering a 'qualified defence of Firestone's thesis' ${ }^{3}$ Chapters nine and ten offer a Firestonian account of contemporary reproductive politics-issues raised by IVF, egg-freezing, surrogacy, and the increasing criminalisation of women judged to have endangered their 'unborn child'.

Chapter three opens with Firestone's claim that 'Anyone observing animals mating, reproducing, and caring for their young will have a hard time accepting the "cultural relativity" line'. ${ }^{4}$ For Firestone, women's oppression is transcultural and transhistorical, arising from women's role in human reproduction, something that makes them dependent on men. Margree suggests that feminist aversion to such an argument stems from repeated confrontation with defences of male dominance couched in biological arguments. She argues that treating women's oppression as 'natural' does not mean that it is right or good-disease and death are also natural after all. Firestone thinks that nature explains women's oppression but does not justify it. Margree unpacks how Firestone engages with the work of Simone de Beauvoir to argue that human society does not passively submit to nature, but rather takes control of it. Logically, if human reproduction causes women's oppression then we need to take control of the means of human reproduction.

Chapter four elaborates on Firestone's concept of sex-class as the firstclass division. This chapter also explains why Firestone called her book 'the dialectic of sex'. She aspired to incorporate Marx's analysis of capitalism into a feminist analysis of women's oppression, thus correcting Marx's

2 Victoria Margree, Neglected or Misunderstood: The Radical Feminism of Shulamith Firestone (Winchester: Zero Books, 2018), 19.

3 Neglected or Misunderstood, 6.

4 Neglected or Misunderstood, 20. 
shortcomings in this area. Firestone thought eliminating private property was a necessary but not sufficient condition for women's liberation. She argued that, historically, most women have been at the 'mercy of their biology' and expected to spend much of their lives pregnant or nursing infants while suffering all the ills associated with their reproductive system such as menstruation and menopause. ${ }^{5}$ Consequently, women depended on men for their physical survival and men have used this advantage to consolidate their power. Male enjoyment of power over women led them to seek domination over other groups of men. Thus, Firestone suggested that the initial sex-class division of humanity is at the root of all other class, caste, and racial forms of domination. However, in late- $20^{\text {th }}$-century technological conditions, women's oppression is no more inevitable than the flooding of a village due to poor flood defences: human beings now have the technological capacity to solve the problem but have so far failed to do so.

Margree ends chapter four by posing several questions to the reader in anticipation of possible objections to Firestone's argument. Do we accept that fertility necessarily meant women's dependence on men for food and shelter in the distant past? On what grounds could this assumption be contested? Even if we accept that most women did depend on men, why should we assume men responded by enjoying and seeking to extend their power? Might not they have responded with tenderness and compassion? Margree suggests that Firestone could be interpreted as making claims about the kind of culture that could develop in such conditions rather than predicting the psychological response of every man. She contends that Firestone offers a plausible theory which feminists should take seriously rather than dismiss out of hand.

Firestone famously described childbirth as 'like shitting a pumpkin', a phrase Margree uses for the title of chapter five, which provides a fascinating discussion of Beauvoir's influence on Firestone, namely her apparent disgust with human reproductive biology. She sets Firestone and Beauvoir in debate with maternalist forms of feminism that celebrate pregnancy, birth, and maternal qualities in the face of patriarchal denigration of women as

5 Neglected or Misunderstood, 25. 
biologically inferior. Margree concludes that while feminists may have legitimate criticisms of Firestone's characterisation of human biological reproduction as barbaric, Firestone's core argument does not depend on this characterisation; further, maternalist feminism tends to over-romanticise women's experience of human reproduction equally as much as Firestone catastrophises it.

The next chapter, 'Against the Nuclear Family', delves into Firestone's engagement with Freud. She called Freudianism 'misguided feminism' because she thought that Freud shared feminists' insights into the terrible psychological damage caused by a father-dominated family structure. Where Freudianism went wrong, she believed, was in seeking to therapeutically reconcile individuals to this patriarchal structure. Margree argues that Firestone misreads Freud and pays little attention to his concept of layered human consciousness. However, she argues that Firestone's critique of the nuclear family and the damage its power dynamics cause for men, women, and children does not need to rest on Freudian theory.

Margree takes Firestone to task for attempting to explain racism in terms of the psychological structure of the nuclear family. Margree considers this the weakest part of The Dialectic of Sex, arguing that Firestone's theory of sexism as the bedrock of all other forms of oppression is one of the more profound problems of her theorising. Margree also notes that, for the most part, Firestone discusses women as though all women share similar experiences, and only briefly discusses black women in her chapter on race.

In chapter seven, 'The 1984 Trope', Margree considers how Firestone confronts cultural imaginings of future technologies as dystopian and dehumanising. Margree argues that Firestone sees the fear of technology as rooted in a fear of dehumanisation in a world where 'technocratic values of efficiency, quantification and control' dominate. ${ }^{6}$ Margree argues that previous theorists like Donna Haraway have misunderstood Firestone as a technological determinist and optimist. In fact, for Firestone, feminist agency is key to the potential of reproductive technologies. Firestone argues that technology has been misused because science is male dominated, and

6 Neglected or Misunderstood, 69. 
sexism has produced a schism between science and the humanities. In a male-dominated culture where human feeling is supressed, science reflects the worst of the male vices, generating horrors like the atomic bomb. Scientists have failed to develop efficient fertility control and artificial means of reproduction because science is a male-dominated field. Thus, Firestone argues that to free themselves from biological reproduction women must become scientists.

Chapter eight elaborates upon Firestone's vision of a post-revolutionary society. Firestone predicted that technological developments would increase unemployment and produce new service-sector jobs, opening low-paid opportunities for women and somewhat eroding male power in the household. Such developments would hasten a feminist-socialist revolution. Immediate revolutionary tasks would involve the equal distribution of drudgery: everyone would have to do some basic necessary work regardless of age or prestige. In the longer term, technology would eliminate drudgery altogether. People would then be allocated resources according to need and would pursue work that intrinsically interested them. Reproduction would no longer be the culturally valued life goal-nonreproductive lifestyles and living arrangements would arise. Some groups of adults may choose to share a household and raise children born through artificial reproduction who would not be biologically related to them. However, child-rearing would not be based on a sense of ownership of the child. Childhood would not be artificially prolonged, and children would be free to leave households where they were unhappy. The abolition of the nuclear family would transform sexuality so that humans would return to Freud's description of infant polymorphous perversity. Sexual distinctions would no longer have significance, and everyone would be androgynous and pansexual.

Margree criticizes Firestone's lapse into the assumption that natural, undistorted human sexuality would be good, containing no impulses for possession, control, or delight in inflicting suffering. She also questions how androgynous norms would treat people who identify more with one gender than another or who wish to reproduce the old-fashioned way. She notes 
that androgyny is not the same as non-binary gender systems, in which differences in gender expression proliferate, but rather suggests a sameness from which some will surely diverge. Nevertheless, Margree argues that attempting to imagine alternatives to current family structures is valuable and suggests that Firestone offered a "literary image" of future possibilities' rather than a literal blueprint for the post-revolutionary future. ${ }^{7}$

The final two chapters discuss present-day reproductive politics through a Firestonian lens. Chapter nine considers IVF, egg-freezing, and surrogacy. Margree problematises the cultural imperative to have children that fuels commercial egg-freezing services. She questions the social organisation of production and precarious employment that mean women cannot chose to bear children when it is biologically optimal. Her discussion of surrogacy criticizes commercial reproductive businesses that prey on peoples' desperation to reproduce, leaving many deeply indebted. She also notes how surrogacy businesses recruit surrogates from poor countries and sometimes confine them to supervised premises where they must follow tightly restricted health and diet regimes. Margree argues that commercial surrogacy commodifies both surrogate and child. Chapter 10, 'Pregnancy on Trial', discusses feticide laws, originally designed to criminalise attacks on pregnant women which result in the death of a foetus. More recently, in the US, such laws have been used to charge pregnant women with reckless conduct causing the death of their foetus. Women of colour are disproportionately targeted by such laws.

Margree makes an effective case for the relevance of Firestone's work. She concisely identifies and addresses common criticisms of Firestone: biological and technological determinism, a naïve faith in the positive impact of technological advances, and a construction of the pregnant female body as wretched and repulsive. She acknowledges flaws, particularly in relation to racism, thoughtless homophobia, problematic assumptions about sexuality, and the assumption that 'a woman is a person with a womb' ${ }^{8}$ Nevertheless, she demonstrates that Firestone's confronting vision and radical impulses

$7 \quad$ Neglected or Misunderstood, 109.

8 Neglected or Misunderstood, 5. 
provide an important resource for a 'genuinely oppositional feminism' in the face of contemporary neoliberal appropriations of feminist discourse that are used to sell cosmetics or justify military interventions. ${ }^{9}$ 